\title{
Reporting funding source or conflict of interest in abstracts of randomized controlled trials, no evidence of a large impact on general practitioners' confidence in conclusions, a three-arm randomized controlled trial
}

\author{
Céline Buffel du Vaure ${ }^{1,2,3}$, Isabelle Boutron ${ }^{1,2,4,5^{*}}$, Elodie Perrodeau ${ }^{1,2,4}$ and Philippe Ravaud ${ }^{1,2,4,5,6}$
}

\begin{abstract}
Background: Systematic reporting of funding sources is recommended in the CONSORT Statement for abstracts. However, no specific recommendation is related to the reporting of conflicts of interest (Col). The objective was to compare physicians' confidence in the conclusions of abstracts of randomized controlled trials of pharmaceutical treatment indexed in PubMed.

Methods: We planned a three-arm parallel-group randomized trial. French general practitioners (GPs) were invited to participate and were blinded to the study's aim. We used a representative sample of 75 abstracts of pharmaceutical industry-funded randomized controlled trials published in 2010 and indexed in PubMed. Each abstract was standardized and reported in three formats: 1) no mention of the funding source or Col; 2) reporting the funding source only; and 3) reporting the funding source and Col. GPs were randomized according to a computerized randomization on a secure Internet system at a 1:1:1 ratio to assess one abstract among the three formats. The primary outcome was GPs' confidence in the abstract conclusions ( 0 , not at all, to 10 , completely confident). The study was planned to detect a large difference with an effect size of 0.5 .

Results: Between October 2012 and June 2013, among 605 GPs contacted, 354 were randomized, 118 for each type of abstract. The mean difference (95\% confidence interval) in GPs' confidence in abstract findings was $0.2(-0.6 ; 1.0)(P=0.84)$ for abstracts reporting the funding source only versus no funding source or Col; -0.4 $(-1.3 ; 0.4)(P=0.39)$ for abstracts reporting the funding source and Col versus no funding source and Col; and -0.6 $(-1.5 ; 0.2)(P=0.15)$ for abstracts reporting the funding source and Col versus the funding source only.

Conclusions: We found no evidence of a large impact of trial report abstracts mentioning funding sources or Col on GPs' confidence in the conclusions of the abstracts.

Trial Registration: ClinicalTrials.gov identifier: NCT01679873

Keywords: Funding, Conflict of interest, General Practitioner, Abstract, Reporting
\end{abstract}

\footnotetext{
* Correspondence: isabelle.boutron@htd.aphp.fr

'METHODS Team, Epidemiology and Statistics Sorbonne Paris Cité Research Centre UMR 1153, INSERM, Paris, France

2Université Paris Descartes, Faculté de Médecine, Paris, France

Full list of author information is available at the end of the article
} 


\section{Background}

The source of funding of clinical trials and researchers' conflicts of interest (CoI) are a major cause for concern in clinical research. Several empirical studies showed that pharmaceutical industry-funded trials more often report positive conclusions than do non-industry-funded trials [1-4]. Internal industry documents, which have become public because of litigation, have revealed how industry trials selectively report favorable results and modify the interpretation of results to favor their drug $[5,6]$. Similarly, the financial relationship among industry, scientific investigators and academic institutions can affect the presentation and interpretation of clinical trial results [7-11].

To deal with these issues, some initiatives have aimed to increase transparency in medical research. The American Medical Association encourages physicians to regularly update all their financial and $\mathrm{CoI}$ disclosures required by employers, advisory bodies and entities funding research. The Physician Payment Sunshine Act requires manufacturers of drugs, devices, biologicals or medical supplies to report annually certain payments or other transfers of value to physicians and teaching hospitals. The manufacturers' reports will be available on a public searchable website [12]. The International Committee of Medical Journal Editors (ICMJE) recommends that all authors who submit a manuscript complete the ICMJE Uniform Disclosure Form for Potential Conflicts of Interest $[13,14]$. Finally, the CONSORT Statement for abstracts recommends reporting the funding source in the abstract of randomized trials and in the full-text articles [15,16]. However, despite these recommendations, the funding source and CoI are frequently inadequately reported [17-20]. For example, despite the CONSORT Statement for abstracts, the funding source is reported in less than $20 \%$ of abstracts for randomized controlled trials (RCTs) published in high-impact-factor journals [21], and author CoI are usually not reported in abstracts for RCTs.

The reporting of the trial funding source and the authors' financial CoI could affect readers' interpretations. Some studies showed that disclosure of the funding source or authors' financial CoI in abstracts can lead readers to discount the results of a trial [22,23]. Recently, Kesselheim and colleagues showed that the reporting of industry funding in abstracts negatively affected readers' interpretations independent of the trial's quality [24]. However, most of these studies involved a small number of abstracts representing hypothetical scenarios of clinical trials evaluating a new drug [24,25]. Furthermore, these studies did not compare the effect of reporting both the trial funding source and the authors' financial CoI.

We aimed to compare the confidence of primary-care physicians in the conclusions of a large representative sample of abstracts for RCTs of pharmaceutical treatment indexed in PubMed reported with or without mention of the funding source and/or authors' financial CoI.

\section{Methods}

\section{Trial design}

We planned a three-arm parallel-group RCT with a sample of representative abstracts of RCTs of pharmaceutical treatment indexed in PubMed, each reported with 1) no mention of the funding source or authors' financial CoI, 2) the funding source only or 3) the funding source and CoI.

We obtained ethics approval from the Institutional Review Board of Paris Descartes University, Paris, France (no. 2012-A00032-41), and the protocol is registered at ClinicalTrials.gov (NCT01679873).

The study was funded by a grant from the Fondation pour la RechercheMédicale (EquipeEspoir de la Recherche, 2010). The funders were not involved in the study design; data collection, analysis, or interpretation; the writing of the article; or the decision to submit for publication.

\section{Selection of randomized controlled trials indexed in PubMed} We selected a sample of RCTs indexed in PubMed and published from 1 January 2010 to 31 December 2010 in the Core Clinical Journals (a subset of 119 widely read journals published in English, covering all specialties of clinical medicine and public-health sciences and including all major medical journals). The search strategy is detailed in Additional file 1. One researcher screened all retrieved citations on the title, abstract and the full text when necessary. The eligibility criteria were an industry-funded RCT with at least one author having a financial CoI, testing superiority, assessing pharmaceutical treatment (drugs) prescribed in a primary-care setting (defined as drugs that may be prescribed by a general practitioner (GP) or prescribed for diseases managed jointly by a specialist and a GP), with a conclusion in favor of the beneficial effect of the experimental treatment.

Exclusion criteria were investigation of nonpharmaceutical treatments (that is, medical devices, patient education), equivalence or noninferiority trials, safety trials, trials assessing different pharmacological procedures, and abstracts reporting a negative or neutral conclusion. One researcher (CB), who is an assistant professor in primary care, screened all retrieved abstracts and selected abstracts following these inclusion criteria. In cases of doubt regarding the inclusion of an abstract, a second researcher (IB) evaluated the abstract to achieve consensus.

From the selected reports, the reviewer systematically extracted the industry funding source and all authors' financial CoI. If these data were not reported in the abstract or full-text article, the abstract was excluded.

Of the 2,797 citations screened, reports of 75 RCTs were selected [see Additional files 2 and 3]. In 29 reports 
(37\%), all authors had financial CoI. In 62 (81\%), more than $50 \%$ of the authors had financial CoI. In 58 (77\%), authors who had financial CoI were industry employees and were the first, second or last author in 34 (45\%) reports.

\section{Abstract construction}

The abstracts for all selected RCTs were standardized and modified. The journal name, date and registration number at ClinicalTrials.gov were deleted. Authors' names were substituted by names randomly selected among the 200 names most common in the United Kingdom [see Additional file 4]. Treatments were referred to as 'experimental treatment $\mathrm{A}^{\prime}$ or 'experimental treatment B'. Acronyms used for the study were deleted and dates in the text were modified to avoid trial recognition. Furthermore, each abstract was translated into French. As a quality procedure, three GPs read all abstracts to ensure the quality of the translation and the relevance of the abstracts for GPs.

The abstract for each RCT was reported in three formats as follows:

- Abstract with no mention of the funding source or $\mathrm{CoI}$. If the funding was reported in the original abstract, it was removed.

- Abstract reporting the funding source only. A heading 'FUNDING' was added after the abstract conclusions. Under this heading, we reported the name of the pharmaceutical industry funding the trial.

- Abstract reporting the funding source and CoI. Two headings were added after the abstract conclusions. Under the first heading 'FUNDING', we reported the name of the pharmaceutical industry funding the trial. Under the second heading 'CONFLICTS OF INTEREST, we reported the initials of authors who 1) were employed by the industry and 2) had a financial interest and/or other relationship with the industry (for example, fees, travel costs, stock options, link with a family member employed by the industry). The number of authors with CoI varied in the RCT reports (for $37 \%$ of abstracts, all authors had financial CoI; for $81 \%$, more than $50 \%$ of authors had financial CoI; for $45 \%$, the first, second or last author was employed by the pharmaceutical industry) (see examples in Table 1).

Consequently, we had 225 versions of the 75 abstracts selected: 75 with no mention of the funding source or CoI, 75 reporting the funding source only, and 75 reporting the funding source and $\mathrm{CoI}$.

Selection of general practitioners and recruitment procedures Eligible participants were French GP members of a network of GPs involved in clinical research. GPs were from all over France and had part-time activity in a university general practice department as a teacher or student supervisor.

GPs were invited by email to participate in a study evaluating the interpretation of abstracts of RCTs (with three reminders) or by an investigator during the national annual medical congress for general practice. We used two different sources of recruitment for pragmatic reasons. Such a strategy is very often used in most RCTs to increase the sample size and the generalizability of the study results. The GPs were informed that their participation would involve reading only one abstract of an RCT and answering some questions about their interpretation of the abstract. They were informed that the collected data would remain anonymous and that we would inform them of the study results when available. However, they did not know that abstracts were modified and that several formats were compared. As approved by the ethics committee, participant consent was considered obtained as soon as they logged onto the survey site. If GPs agreed to participate, they had to complete a questionnaire related to their general characteristics. They were instructed to carefully read one abstract that was randomly selected for them and they had to answer questions related to their interpretation of this abstract (see Outcomes and Additional files 5 and 6).

\section{Randomization and blinding of general practitioners}

An independent statistician created a computerized randomization list with a 1:1:1 ratio using random block sizes. The sequence was generated to have the same number of assessments for each of the three formats of a given abstract. A computer engineer uploaded the randomization list to a secure Internet system to assure allocation concealment. Participants logged onto this secure Internet system and were randomized to assess one of the 75 abstracts presented in one of the three formats.

Participants were informed that the aim of the study was to assess their interpretation of RCT abstracts, but they did not know that abstracts were modified and that several formats were compared.

\section{Outcomes}

The primary outcome was GPs' confidence in the abstract's conclusions. GPs answered the following question: 'On a scale ranging from 0 to 10 , indicate your confidence in the conclusion reported,' with 0 , not at all confident, to 10 , completely confident. The secondary endpoints were the perceived methodological quality of the study and the interpretation of the treatment benefit in terms of safety and efficacy. For these outcomes, GPs were asked 'On a scale ranging from 0 to 10 , what is the methodological quality of the study?' with 0 , very poor quality, to 10 , excellent quality, and 'On a scale ranging from 0 to 10 , is the experimental treatment beneficial in 


\section{Table 1 Examples of abstracts assessed}

\section{Abstract with no mention of funding source and $\mathrm{Col}$}

Efficacy and safety of experimental treatment $A$ in combination with treatment $B$ and treatment $c$ in patients with mixed dyslipidemia.

AUTHORS: Thomson MR; Cook A; Pettigrew GE; Bower G; Bishop D; Potter LM; Alyn JC

BACKGROUND: Treatment $B$ and treatment $C$ combination therapy may be insufficient to improve lipid and nonlipi parameters beyond low-density lipoprotein cholestero

(LDL-C) in patients with mixed dyslipidemia.

METHODS: In this phase 3, multicenter, double-blind study a total of 543 patients with triglycerides $>/=150 \mathrm{mg} / \mathrm{dL}$ and $<400 \mathrm{mg} / \mathrm{dL}$, high-density lipoprotein cholesterol $(\mathrm{HDL}-\mathrm{C})<40 \mathrm{mg} / \mathrm{dL}$ ( $<50 \mathrm{mg} / \mathrm{dL}$ for women), and LDL-C $>/=130 \mathrm{mg} / \mathrm{dL}$ were randomized to 12 weeks of treatment with experimental treatment A $135 \mathrm{mg}$ or placebo, each coadministered with treatment B $40 \mathrm{mg}+$ treatment $C$ $10 \mathrm{mg}$ (treatment $\mathrm{BC}$ ).

RESULTS: Both treatment regimens lowered LDL-C by $>50 \%$ however, experimental treatment $A$ and treatment $B C$ resulted in significantly $(P<.001)$ greater improvements in HDL-C $(13.0 \%$ vs $4.2 \%)$, triglycerides $(-57.3 \%$ vs $-39.7 \%)$, non-HDL-C $(-55.6 \%$ vs $-51.0 \%)$, and apoprotein B $(-49.1 \%$ vs $-44.7 \%)$ compared with treatment BC. Overall, adverse events were similar in the 2 treatment groups. No unexpected muscle, hepatic, or renal safety signals were identified with either treatment combination.

CONCLUSIONS: In patients with mixed dyslipidemia, the combination of experimental treatment $\mathrm{A}+$ treatment $\mathrm{BC}$ significantly improved lipid and nonlipid parameters compared with treatment BC and was generally well tolerated.

\section{Abstract reporting funding source only}

Efficacy and safety of experimental treatment $A$ in combination with treatment $B$ and treatment $c$ in patients with mixed dyslipidemia.

AUTHORS: Thomson MR; Cook A; Pettigrew GE; Bower G; Bishop D; Potter LM; Alyn JC

BACKGROUND: Treatment B and treatment $C$ combination therapy may be insufficient to improve lipid and nonlipid parameters beyond low-density lipoprotein cholesterol (LDL-C) in patients with mixed dyslipidemia.

METHODS: In this phase 3, multicenter, double-blind study, a total of 543 patients with triglycerides $>/=150 \mathrm{mg} / \mathrm{dL}$ and $<400 \mathrm{mg} / \mathrm{dL}$, high-density lipoprotein cholesterol (HDL-C) $<40 \mathrm{mg} / \mathrm{dL}(<50 \mathrm{mg} / \mathrm{dL}$ for women), and LDL-C $>/=130 \mathrm{mg} / \mathrm{dL}$ were randomized to 12 weeks of treatment with experimental treatment A $135 \mathrm{mg}$ or placebo, each coadministered with treatment B $40 \mathrm{mg}$ + treatment $C$ $10 \mathrm{mg}$ (treatment BC).

RESULTS: Both treatment regimens lowered LDL-C by $>50 \%$; however experimental treatment $A$ and treatment $B C$ resulted in significantly $(P<.001)$ greater improvements in HDL-C

( $13.0 \%$ vs $4.2 \%)$, triglycerides (-57.3\% vs $-39.7 \%)$, non-HDL-C $(-55.6 \%$ vs $-51.0 \%)$, and apoprotein B (-49.1\% vs $-44.7 \%)$ compared with treatment BC. Overall, adverse events were similar in the 2 treatment groups. No unexpected muscle, hepatic, or renal safety signals were identified with either treatment combination

CONCLUSIONS: In patients with mixed dyslipidemia, the combination of experimental treatment $\mathrm{A}+$ treatment $\mathrm{BC}$ significantly improved lipid and nonlipid parameters compared with treatment BC and was generally well tolerated.

FUNDING: Abbott
Abstract reporting funding source and $\mathrm{Col}$

Efficacy and safety of experimental treatment $A$ in combination with treatment $B$ and treatment $c$ in patients with mixed dyslipidemia.

AUTHORS: Thomson MR; Cook A; Pettigrew GE; Bower G; Bishop D; Potter LM; Alyn JC

BACKGROUND: Treatment B and treatment $C$ combination therapy may be insufficient to improve lipid and nonlipid parameters beyond low-density lipoprotein cholesterol (LDL-C) in patients with mixed dyslipidemia.

METHODS: In this phase 3, multicenter, double-blind study a total of 543 patients with triglycerides $>/=150 \mathrm{mg} / \mathrm{dL}$ and $<400 \mathrm{mg} / \mathrm{dL}$, high-density lipoprotein cholesterol (HDL-C) $<40 \mathrm{mg} / \mathrm{dL}$ ( $<50 \mathrm{mg} / \mathrm{dL}$ for women), and LDL-C $>/=130 \mathrm{mg} / \mathrm{dL}$ were randomized to 12 weeks of treatment with experimental treatment A $135 \mathrm{mg}$ or placebo, each coadministered with treatment B $40 \mathrm{mg}$ + treatment C $10 \mathrm{mg}$ (treatment BC).

RESULTS: Both treatment regimens lowered LDL-C by $>50 \%$; however, experimental treatment $\mathrm{A}$ and treatment $\mathrm{BC}$ resulted in significantly $(\mathrm{P}<.001)$ greater improvements in $\mathrm{HDL}-\mathrm{C}$

$(13.0 \%$ vs $4.2 \%)$, triglycerides $(-57.3 \%$ vs $-39.7 \%)$, non-HDL-C $(-55.6 \%$ vs $-51.0 \%)$, and apoprotein B (-49.1\% vs $-44.7 \%)$ compared with treatment BC. Overall, adverse events were similar in the 2 treatment groups. No unexpected muscle, hepatic, or renal safety signals were identified with either treatment combination

CONCLUSIONS: In patients with mixed dyslipidemia, the combination of experimental treatment $\mathrm{A}+$ treatment $\mathrm{BC}$ significantly improved lipid and nonlipid parameters

compared with treatment $\mathrm{BC}$ and was generally well tolerated.

\section{FUNDING: Abbott.}

CONFLICTS OF INTEREST: MRT, AC and GEP declared financial interest and/or other relationships with Abbott. $G B$ DB, LMP and JCA are employees of Abbott. 
terms of safety and efficacy?' with 0 , not at all beneficial, to 10 , totally beneficial.

Details of the questionnaire are in Additional file 6.

\section{Sample size}

With a significance level of $1.67 \%$ fixed for each of the three $2 \times 2$ comparisons (Bonferroni correction to maintain an overall significance level of 5\%), we needed 118 evaluations for each format to demonstrate an effect size of 0.5 on the numeric scale with a power of $90 \%$ for each $2 \times 2$ comparison. Because we expected that each participant would read a single abstract, we needed to include 118 participants per arm (354 in total).

\section{Statistical analysis}

Descriptive results are reported with means and standard deviations (SDs), median and interquartile ranges (Q1 to Q3) for quantitative variables and frequencies and percentages by modality for qualitative variables.

We had three main comparisons: abstracts with no mention of the funding source or CoI versus reporting the funding source only; abstracts with no mention of the funding source or CoI versus reporting the funding source and CoI; and abstracts reporting the funding source only versus reporting the funding source and CoI. Differences in primary outcome between groups were estimated by a linear model and were compared by Tukey's honestly significant difference test to adjust for multiple testing [26]. Differences in secondary outcomes were compared in the same manner as for the primary outcome. Post hoc sensitivity analysis adjusted on the mode of recruitment were performed. All analyses involved use of R software v3.0.1 [27].

\section{Results}

\section{General practitioner characteristics}

The flow of participants is shown in Figure 1. Between October 2012 and June 2013, among 605 GPs contacted, 354 (58\%) agreed to participate, and 118 were allocated to each arm. The characteristics of GPs are given in Table 2. In all, 65\% were men; the median (Q1 to Q3) age was 51 (36 to 57 ). Less than half (43\%) had participated in a pharmaceutical industry-funded clinical trial. Only $22 \%$ had received some fees from the pharmaceutical industry for speaking, consulting or enrolling patients in trials. Half had not received any visits from pharmaceutical industry representatives.

\section{General practitioners' confidence in abstract conclusions} Abstracts were read by a median of six GPs (Q1 to Q3, 3 to 6). In all, 34 abstracts were read three times (once in each group), 39 were read six times (twice in each group) and two were read nine times (three times in each group).

Data on the mean (SD) GP confidence in abstract conclusions are reported in Table 3. The mean difference
(95\% confidence interval $(\mathrm{CI})$ ) in confidence with conclusions was $0.2(-0.6 ; 1.0)(P=0.84)$ for abstracts reporting the funding source only versus no funding source or CoI; $-0.4(-1.3 ; 0.4)(P=0.39)$ for abstracts reporting the funding source and $\mathrm{CoI}$ versus no funding source or CoI; and $-0.6(-1.5 ; 0.2)(P=0.15)$ for abstracts reporting the funding source and $\mathrm{CoI}$ versus the funding source only (Table 3 ). The adjusted post-hoc analysis did not obtain exactly the same results as the analysis that was not adjusted on the mode of recruitment. However the adjusted results were very consistent and confirm that the results are robust (see Additional file 7).

\section{General practitioners' perception of trial methodological quality and treatment benefit}

The mean difference $(95 \% \mathrm{CI})$ in perception of quality was $0.1(-0.7 ; 0.9)(P=0.97)$ for abstracts reporting the funding source only versus no funding source or CoI; -0.4 $(-1.2$; 0.4$)(P=0.41)$ for abstracts reporting the funding source and $\mathrm{CoI}$ versus no funding source or $\mathrm{CoI}$; and -0.5 $(-1.3 ; 0.3)(P=0.30)$ for abstracts reporting the funding source and CoI versus the funding source only (Table 3 ).

The mean difference $(95 \% \mathrm{CI})$ in assessment of treatment benefit was $-0.1(-1.0 ; 0.7)(P=0.93)$ for abstracts reporting the funding source only versus no funding source or CoI; $-0.8(-1.7 ; 0.02)(P=0.06)$ for abstracts reporting the funding source and $\mathrm{CoI}$ versus no funding source or CoI; and $-0.7(-1.5 ; 0.1)(P=0.13)$ for abstracts reporting the funding source and $\mathrm{CoI}$ versus the funding source only (Table 3).

\section{Discussion}

This RCT assessed the impact of reporting a funding source and/or financial CoI in trial report abstracts on GPs' interpretation of trial results reported in the abstracts' conclusions. We used a large representative sample of abstracts of RCTs indexed in PubMed but did not find a statistically significant difference in GPs' confidence in the abstracts' conclusions, assessment of trial methodological quality or perception of treatment benefit.

Although one study showed that physicians were not influenced by disclosure statements in trial reports [25], most studies evaluating how physicians interpret research funding disclosures showed that abstracts reporting a funding source or CoI could modify readers' interpretation [22-24]. In contrast, our results did not show a statistically significant difference in GPs' interpretation of an abstract's findings by the disclosure statements. However, our confidence intervals were wide, with an effect going in the same direction, and confidence in abstract conclusions was surprisingly low, 3.6 on a scale from 0 to 10 . Therefore, we cannot exclude an effect, particularly for abstracts reporting both a funding source and authors' CoI. 


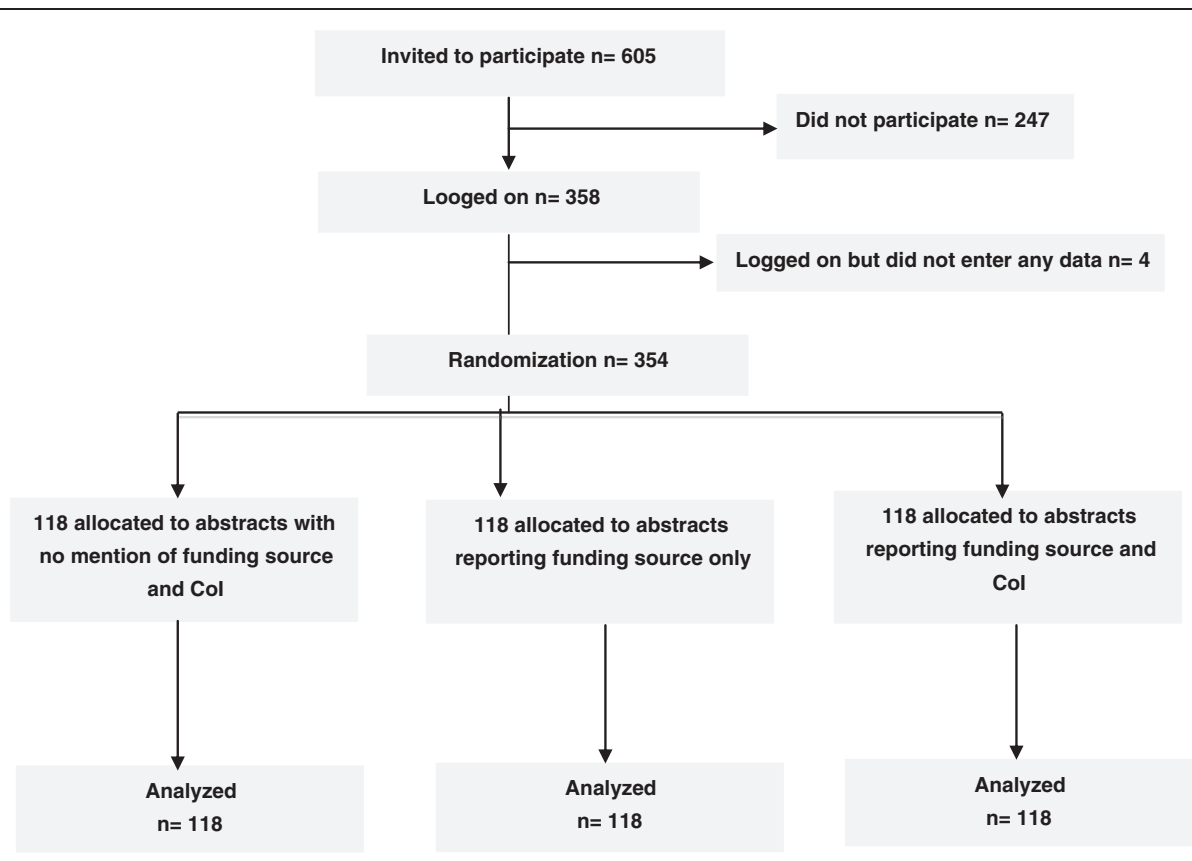

CoI, conflicts of interest

Figure 1 Flow diagram of general practitioner evaluators in the study.

Previous studies evaluated physicians' interpretation of specifically developed vignettes or abstracts of hypothetical trials [22,24] or used the abstract of a single trial [23]. Contrary to these studies, we aimed to have a pragmatic approach and used abstracts from a large sample of real trials. We selected a representative sample of abstracts of RCT reports published in 2010 and indexed in PubMed, and we systematically recorded the funding source and authors' CoI for these trials. To avoid bias, all information that could allow readers to identify the trial or drug investigated

Table 2 General characteristics of general practitioner (GP) evaluators of abstracts of randomized controlled trials of pharmaceutical treatments

\begin{tabular}{|c|c|c|c|c|}
\hline GP characteristics & $\begin{array}{c}\text { All GPs } \\
\text { number }=354\end{array}$ & $\begin{array}{c}\text { Abstracts with no mention } \\
\text { of funding source or Col } \\
\text { number }=118\end{array}$ & $\begin{array}{c}\text { Abstracts reporting } \\
\text { funding source only } \\
\text { number }=118\end{array}$ & $\begin{array}{c}\text { Abstracts reporting } \\
\text { funding source and } \\
\text { Col number }=118\end{array}$ \\
\hline Gender (male) - number (\%) & $227(64.9)$ & $78(66.7)$ & $76(65.5)$ & $73(62.4)$ \\
\hline Age, years - median (Q1 to Q3) & $51.4(36.4 ; 57.3)$ & $48.7(37.1 ; 56.3)$ & $51.8(36.2 ; 57.6)$ & $52.7(37.4 ; 57.2)$ \\
\hline Receive fees from pharmaceutical industry - number (\%) & $75(21.6)$ & $30(26.3)$ & $20(17.1)$ & $25(21.6)$ \\
\hline For performing a presentation & $22(6.3)$ & $8(7.0)$ & $7(6.0)$ & $7(6.0)$ \\
\hline For consulting & $16(4.6)$ & $4(3.5)$ & $6(5.1)$ & $6(5.2)$ \\
\hline For enrolling patients in a trial & $60(17.3)$ & $26(22.8)$ & $18(15.4)$ & $16(13.8)$ \\
\hline $\begin{array}{l}\text { Participate (current or past) in a trial funded by } \\
\text { pharmaceutical industry - number (\%) }\end{array}$ & $151(43.5)$ & $54(47.4)$ & $47(40.2)$ & $50(43.1)$ \\
\hline \multicolumn{5}{|l|}{$\begin{array}{l}\text { Receive visits from medical representatives of } \\
\text { pharmaceutical industry - number (\%) }\end{array}$} \\
\hline None & $174(50.1)$ & $56(49.1)$ & $59(50.4)$ & $59(50.9)$ \\
\hline 1 to 5 per month & $84(24.2)$ & $30(26.3)$ & $25(21.4)$ & $29(25.0)$ \\
\hline 6 to 10 per month & $54(15.6)$ & $17(14.9)$ & $21(17.9)$ & $16(13.8)$ \\
\hline$>10$ per month & $35(10.1)$ & $11(9.6)$ & $12(10.3)$ & $12(10.3)$ \\
\hline
\end{tabular}

Col, conflicts of interest. 
Table 3 Comparison of GPs' confidence in the abstract's conclusions, methodological quality and treatment benefit

\begin{tabular}{|c|c|c|c|c|c|c|}
\hline & $\begin{array}{l}\text { Abstracts with no } \\
\text { mention of funding } \\
\text { source or Col } \\
\text { number }=118\end{array}$ & $\begin{array}{c}\text { Abstracts reporting } \\
\text { funding source only } \\
\text { number }=118\end{array}$ & $\begin{array}{l}\text { Abstracts reporting } \\
\text { funding source and } \\
\text { Col number }=118\end{array}$ & $\begin{array}{l}\text { Abstracts reporting funding } \\
\text { source only versus no } \\
\text { mention of funding } \\
\text { source or Col }\end{array}$ & $\begin{array}{l}\text { Abstracts reporting } \\
\text { funding source and Col } \\
\text { versus no mention of } \\
\text { funding source or Col }\end{array}$ & $\begin{array}{l}\text { Abstracts reporting } \\
\text { funding source and Col } \\
\text { versus funding source only }\end{array}$ \\
\hline Outcomes & Mean (SD) & Mean (SD) & Mean (SD) & Mean difference $(95 \% \mathrm{Cl})$ & Mean difference $(95 \% \mathrm{Cl})$ & Mean difference $(95 \% \mathrm{Cl})$ \\
\hline $\begin{array}{l}\text { Confidence in the abstract } \\
\text { conclusions (scale } 0 \text { to 10) }\end{array}$ & $3.6(2.6)$ & $3.8(2.6)$ & $3.2(2.7)$ & $0.2(-0.6 ; 1.0), P=0.84$ & $-0.4(-1.3 ; 0.4), P=0.39$ & $-0.6(-1.5 ; 0.2), P=0.15$ \\
\hline $\begin{array}{l}\text { Methodological quality of } \\
\text { the study (scale } 0 \text { to } 10 \text { ) }\end{array}$ & $4.5(2.7)$ & $4.6(2.5)$ & $4.1(2.6)$ & $0.1(-0.7 ; 0.9), P=0.97$ & $-0.4(-1.2 ; 0.4), P=0.41$ & $-0.5(-1.3 ; 0.3), P=0.30$ \\
\hline $\begin{array}{l}\text { Treatment benefit in } \\
\text { terms of efficacy and } \\
\text { safety (scale } 0 \text { to 10) }\end{array}$ & $5.0(2.8)$ & $4.8(2.7)$ & $4.1(2.8)$ & $-0.1(-1.0 ; 0.7), P=0.93$ & $-0.8(-1.7 ; 0.02), P=0.06$ & $-0.7(-1.5 ; 0.1), P=0.13$ \\
\hline
\end{tabular}


was deleted or modified by using, for example, fictitious names for authors. Abstracts reporting a negative or neutral conclusion were not included so as to homogenize abstract conclusions and facilitate the interpretation of our results.

In this trial, we evaluated the reporting of both a funding source and authors' CoI in abstracts for several reasons. First, we focused on abstracts because they are an essential mode for disseminating research results [28-30]. Furthermore, the CONSORT statement for abstracts clearly recommends reporting the funding source to improve transparency, but we lack a clear recommendation on the reporting of authors' financial $\mathrm{CoI}$ in abstracts. CoI are defined by a set of circumstances that create a risk that professional judgment or actions regarding a primary interest will be unduly influenced by a secondary interest [31]. CoI are divided into various categories, from financial to non-financial ties, such as personal relationships [32]. In our study, we did not specifically assess CoI other than financial ones. Furthermore, we explored only one factor - reporting funding source and $\mathrm{CoI}$ disclosure - and we acknowledge that in most cases, a multifaceted type of approach is required to change attitudes and behavior.

Our study has some limitations. First, in the context of a study on the interpretation of abstract results, GPs might not have interpreted abstracts as they usually do in clinical practice. Evaluation of how carefully the GPs read the abstract was not done as this is difficult to appraise. Anonymization of abstracts may have distanced the reader and contributed to the low confidence in the abstracts. As well, the low confidence overall suggests that GPs were more suspicious than usual, by searching details with attention. Second, these results may not be applicable to all physicians. The participants in this study were GPs involved in clinical research and/or with part-time activity in a university general practice department as a teacher or student supervisor. Our participants probably have higher expertise in clinical research than the usual French GP. Finally, this study was planned to detect a large effect, and confidence intervals were wide. Therefore, we cannot exclude a smaller effect [33], particularly for abstracts reporting both a funding source and authors' CoI.

\section{Conclusions}

In conclusion, we found no statistically significant difference in GPs' interpretations of findings from abstracts reporting the funding source and/or CoI for RCTs investigating pharmaceutical treatments. However, the mean differences between sets of abstracts had wide confidence intervals and we cannot exclude a possible impact of reporting the funding source and $\mathrm{CoI}$ on readers' interpretation, particularly for abstracts reporting both the funding source and authors' financial CoI.

\section{Additional files}

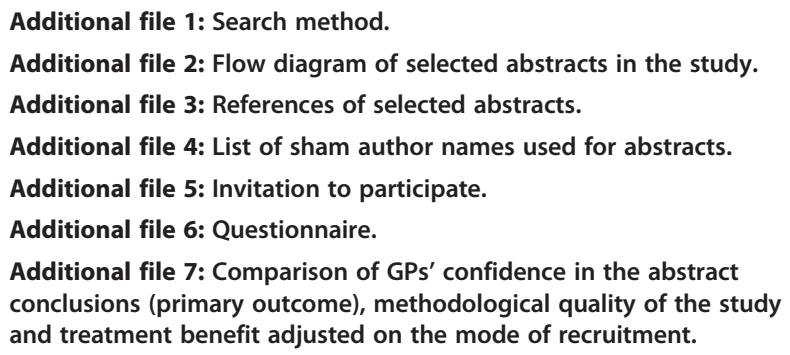

\section{Abbreviations}

Cl: confidence interval; Col: conflicts of interest; GP: general practitioner; ICMJE: International Committee of Medical Journal Editors; Q: interquartile range; RCT: randomized controlled trial; SD: standard deviation.

\section{Competing interests}

$C B$ received honoraria from Pfizer Inc. for participating in clinical research. IB, EP and PR declare they have no conflicts of interest.

\section{Authors' contributions}

All authors were involved in drafting the manuscript. CB and IB were involved in acquiring and interpreting the data. EP analyzed the data. PR gave the final approval of this version of the manuscript. All authors read and approved the final manuscript.

\section{Acknowledgments}

We thank Pr Serge Gilberg for advice and help in recruiting GPs. We thank Julie Cattani and VirginiePersonne for abstract reading and advice, and Viet-Thi Tran for help in recruiting participants. We also thank Laura Smales for critical reading and English correction of the manuscript.

\section{Author details}

${ }^{1}$ METHODS Team, Epidemiology and Statistics Sorbonne Paris Cité Research Centre UMR 1153, INSERM, Paris, France. ²Université Paris Descartes, Faculté de Médecine, Paris, France. ${ }^{3}$ Département de Médecine Générale, Université Paris Descartes, Paris, France. ${ }^{4}$ AP-HP (Assistance Publique des Hôpitaux de Paris), Hôpital Hôtel Dieu, Centre d'Epidémiologie Clinique, Paris, France. ${ }^{5}$ French Cochrane Centre, Paris, France. ${ }^{6}$ Department of Epidemiology, Columbia University Mailman School of Public Health, New York, NY, USA.

Received: 11 October 2013 Accepted: 25 March 2014

Published: 28 April 2014

\section{References}

1. Bekelman J, Li Y, Gross C: Scope and impact of financial conflicts of interest in biomedical research: a systematic review. JAMA 2003, 289:454-465.

2. Sismondo S: How pharmaceutical industry funding affects trial outcomes: causal structures and responses. Soc Sci Med 2008, 66:1909-1914.

3. Rising $K$, Bacchetti $P$, Bero L: Reporting bias in drug trials submitted to the Food and Drug Administration: review of publication and presentation. PLoS Med 2008, 5:e217. discussion e217.

4. Lundh A, Sismondo S, Lexchin J, Busuioc OA, Bero L: Industry sponsorship and research outcome. Cochrane Database Syst Rev 2012, 12:MR000033.

5. Lexchin J, Bero L, Djulbegovic B, Clark O: Pharmaceutical industry sponsorship and research outcome and quality: systematic review. BMJ 2003, 326:1167-1170.

6. Hill KP, Ross JS, Egilman DS, Krumholz HM: The ADVANTAGE seeding trial: a review of internal documents. Ann Intern Med 2008, 149:251-258.

7. Forrow $L$, Taylor $W$, Arnold R: Absolutely relative: how research results are summarized can affect treatment decisions. Am J Med 1992, 92:121-124.

8. Bucher H, Weinbacher M, Gyr K: Influence of method of reporting study results on decision of physicians to prescribe drugs to lower cholesterol concentration. BMJ 1994, 309:761-764.

9. Kjaergard L, Als-Nielsen B: Association between competing interests and authors' conclusions: epidemiological study of randomised clinical trials published in the BMJ. BMJ 2002, 325:249. 
10. Tatsioni A, Siontis GC, loannidis JP: Partisan perspectives in the medical literature: a study of high frequency editorialists favoring hormone replacement therapy. J Gen Intern Med 2010, 25:914-919.

11. Perlis RH, Perlis CS, Wu Y, Hwang C, Joseph M, Nierenberg AA: Industry sponsorship and financial conflict of interest in the reporting of clinical trials in psychiatry. Am J Psychiatry 2005, 162:1957-1960.

12. Kuehn BM: Harmonizing reporting of financial conflicts. JAMA 2013, 309:19.

13. Fontanarosa P: Implementation of the ICMJE form for reporting potential conflicts of interest. JAMA 2010, 304:1496.

14. Drazen J, de Leeuw PW, Laine C, Mulrow C, DeAngelis CD, Frizelle FA, Godlee F, Haug C, Hébert PC, James A, Kotzin S, Marusic A, Reyes H, Rosenberg J, Sahni P, Van der Weyden MB, Zhaori G: Toward more uniform conflict disclosures-the updated ICMJE conflict of interest reporting form. JAMA 2010, 304:212-213.

15. Hopewell S, Clarke M, Moher D, Wager E: CONSORT for reporting randomized controlled trials in journal and conference abstracts: explanation and elaboration. PLoS Med 2008, 5:e20.

16. Schulz KF, Altman DG, Moher D: CONSORT 2010 statement: updated guidelines for reporting parallel group randomized trials. Ann Intern Med 2010, 152:726-732

17. Weinfurt KP, Seils DM, Tzeng JP, Lin L, Schulman KA, Califf RM: Consistency of financial interest disclosures in the biomedical literature: the case of coronary stents. PLoS One 2008, 3:e2128.

18. Forbes TL: Author disclosure of conflict of interest in vascular surgery journals. J VascSurg 2011, 54:55S-58S

19. Okike K, Kocher MS, Wei EX, Mehlman CT, Bhandari M: Accuracy of conflict-of-interest disclosures reported by physicians. N Engl J Med 2009, 361:1466-1474.

20. Chimonas S, Frosch Z, Rothman DJ: From disclosure to transparency: the use of company payment data. Arch Intern Med 2011, 171:81-86.

21. Hopewell S, Ravaud P, Baron G, Boutron I: Effect of editors' implementation of CONSORT guidelines on the reporting of abstracts in high impact medical journals: interrupted time series analysis. BMJ 2012, 344:e4178.

22. Chaudhry S, Schroter S, Smith R, Morris J: Does declaration of competing interests affect readers' perceptions? A randomised trial. BMJ 2002, 325:1391-1392.

23. Schroter S, Morris J, Chaudhry S, Smith R, Barratt H: Does the type of competing interest statement affect readers' perceptions of the credibility of research? Randomised trial. BMJ 2004, 328:742-743.

24. Kesselheim AS, Robertson CT, Myers JA, Rose SL, Gillet V, Ross KM, Glynn RJ, Joffe S, Avorn J: A randomized study of how physicians interpret research funding disclosures. N Engl J Med 2012, 367:1119-1127.

25. Silverman GK, Loewenstein GF, Anderson BL, Ubel PA, Zinberg S, Schulkin J: Failure to discount for conflict of interest when evaluating medical literature: a randomised trial of physicians. $J$ Med Ethics 2010, 36:265-270.

26. Miller RG: Simultaneous Statistical Inference. New York: Springer New York; 1981.

27. Team RC: R: A Language and Environment for Statistical Computing. Vienna: $R$ Foundation for Statistical Computing; 2012.

28. Barry HC, Ebell MH, Shaughnessy AF, Slawson DC, Nietzke F: Family physicians' use of medical abstracts to guide decision making: style or substance? J Am Board FamPract 1998, 14:437-442.

29. Ebell MH, Barry HC, Slawson DC, Shaughnessy AF: Finding POEMs in the medical literature. J FamPract 1999, 48:350-355.

30. The impact of open access upon public health. PLoS Med 2006, 3:e252.

31. Thompson D: Understanding financial conflicts of interest. N Engl J Med 1993, 329:573-576

32. Loewenstein G, Sah S, Cain DM: The unintended consequences of conflict of interest disclosure. JAMA 2012, 307:669-670.

33. Charles P, Giraudeau B, Dechartres A, Baron G, Ravaud P: Reporting of sample size calculation in randomised controlled trials: review. BMJ 2009, 338:b1732.

doi:10.1186/1741-7015-12-69

Cite this article as: Buffel du Vaure et al.: Reporting funding source or conflict of interest in abstracts of randomized controlled trials, no evidence of a large impact on general practitioners' confidence in conclusions, a three-arm randomized controlled trial. BMC Medicine 2014 12:69.

\section{Submit your next manuscript to BioMed Central and take full advantage of:}

- Convenient online submission

- Thorough peer review

- No space constraints or color figure charges

- Immediate publication on acceptance

- Inclusion in PubMed, CAS, Scopus and Google Scholar

- Research which is freely available for redistribution

Submit your manuscript at www.biomedcentral.com/submit
C Biomed Central 